\title{
ISOLATION AND IDENTIFICATION OF NEW YEAST STRAINS FROM BEE BREAD
}

\author{
Marek Kieliszek $^{1 凶}$, Vitaliy Kolotylo ${ }^{1}$, Anna Mikołajczuk-Szczyrba ${ }^{2}$, Liviu Giurgiulescu ${ }^{3}$, \\ Anna M. Kot ${ }^{1}$, Stanisław Kalisz ${ }^{4}$, Katarzyna Pobiega ${ }^{1}$, Andrzej Cendrowski ${ }^{4}$ \\ ${ }^{1}$ Institute of Food Sciences, Department of Food Biotechnology and Microbiology, Warsaw University of Life \\ Sciences - SGGW, 159C Nowoursynowska St., 02-776 Warsaw, Poland; \\ ${ }^{2}$ Prof. Wactaw Dąbrowski Institute of Agricultural and Food Biotechnology, Department of Microbiology, 36 \\ Rakowiecka St., 02-532 Warsaw, Poland; \\ ${ }^{3}$ Chemistry-Biology Department, Technical University of Cluj Napoca, North University Center of Baia Mare, \\ 26 Victoriei St., Romania \\ ${ }^{4}$ Institute of Food Sciences, Department of Food Technology, Warsaw University of Life Sciences - SGGW, \\ 159C Nowoursynowska St., 02-776 Warsaw, Poland \\ $\triangle_{\text {marek_kieliszek@sggw.edu.pl }}$ \\ https://doi.org/10.34302/crpjfst/2021.13.1.17 \\ Article history: \\ Received: \\ 5 February 2020 \\ Accepted: \\ 5 February 2021 \\ Keywords: \\ Bee bread; \\ Bee pollen; \\ Yeast; \\ Microbiology; \\ Isolation DNA.

\section{ABSTRACT} \\ Bee bread is a preserved bee pollen, which is a mixture of plant pollen, \\ nectar, secretions from the digestive system of bees, and a layer of honey. \\ It has a very high nutritional value. Bee bread can be used as dietary \\ supplements due to their rich protein content and the presence of essential \\ amino acids, fatty acids, mineral salts, and vitamins. This work carried out \\ the isolation and identification of yeast strains from bee bread. The \\ obtained strains displayed the phenotypic characteristics of Rhodotorula \\ yeast. The DNA electrophoretic analysis showed a band size of $640 \mathrm{bp}$. \\ Sequencing analysis of the internal transcribed spacer regions of the $5.8 \mathrm{~S}$ \\ rRNA gene confirmed the presence of the yeast Rhodotorula mucilaginosa \\ (MK1).
}

\section{Introduction}

One of the least known and studied bee products is bee bread (Khalifa et al., 2020). During winter and early spring, this product is the only source of food for the bee colony, following honey (Babarinde et al., 2018). It is formed from pollen and provides protein, lipids, vitamins, and minerals for bees. Water constitutes the largest part of the mass of bee feathers, which is present in the amount of 20$30 \%$ of the mass of the fresh product. Proteins (up to $30 \%$ ) constitute the second ingredient with the highest content in the bee bread. Carbohydrates are present at an amount of 13$55 \%$ in the bee bread, with most of them being simple sugars - mainly glucose and fructose (Kieliszek et al., 2018). Fatty acids and vitamins are considered as other significant ingredients. The rich composition of bee bread contributes to its nutritional and healthpromoting properties. The presence of various ingredients, characteristic of natural origin, indicates that bee bread can be successfully used as a supplement and a dietary component (Tomás et al., 2017).

The use of bee bread and its derivatives poses some health risks. The unprocessed bee bread, obtained from the natural environment, may contain microbiological contaminants (Janashia et al., 2018). Insects and various microorganisms are a threat to beekeeping related to the acquisition and processing of bee bugs. The very transformation of pollen into 
bee bread occurs under the influence of biochemical and metabolic processes carried out by bacteria and yeast in the product. Lactic acid bacteria Lactobacillus and Bifidobacterium are the dominant microflora in bee bread, while yeasts (Candida, Saccharomyces, Cryptococcus, Zygosaccharomyces) and molds (including Penicillium, Rhizopus, Trichothecium) (Gilliam et al., 1989; Nogueira et al., 2012) constitute the second significant group of microorganisms. The results of various studies suggest that the microorganisms may be derived partly from pollen and partly from the bees (Gilliam, 1997; de Arruda et al., 2017).

This study aimed to identify and characterize new yeast strains isolated from bee bread using classical microbiology and molecular methods such as polymerase chain reaction (PCR).

\section{Materials and methods}

\subsection{Materials}

\subsubsection{Bee bread}

A natural product originating from beesbee bread - was used as the biological material. The study used bee brood obtained from Lubelskie Voivodeship (Poland). Bee bread was crushed under sterile conditions from honeycombs (Fig. 1).

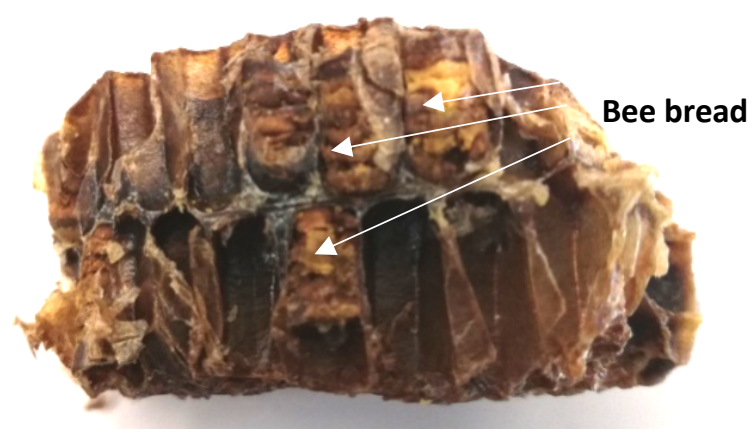

Figure 1. Bee bread in honeycomb.

\subsection{Methods}

\subsubsection{Culture Conditions}

YPD (Yeast Extract-Peptone-Dextrose) liquid medium was used to multiply yeasts from the biological material (bee bread) and isolate them. After adding 3 grains of bee bread to the liquid medium, the mixture was homogenized by vortexing (1 $\mathrm{min})$. Multiplication of the yeast microflora was allowed to occur at $28^{\circ} \mathrm{C}$ for $48 \mathrm{~h}$. Approximately 30 inoculations were performed.

After $48 \mathrm{~h}$, a reduction inoculation of the liquid medium was performed on solid YPD (Petri dishes). Cultures were developed at $28^{\circ} \mathrm{C}$ for $48 \mathrm{~h}$, and those representing each type of colony were isolated and purified by repeated streaking on YPD agar. The obtained pure yeast colonies were used as the basic material for further studies and stored at $4^{\circ} \mathrm{C}$ on YPD slants with $2 \%$ agar.

\subsubsection{Microscopic observations}

The isolated yeast was observed under the OPTA-VIEW optical microscope with Vision 7 software (Poland).

\subsubsection{DNA isolation from yeast cells}

DNA was isolated from yeast cells according to a modified method of BzduchaWróbel et al. (2013). Briefly, liquid yeast cultures were centrifuged (10 $\mathrm{min}, 5000 \mathrm{rpm})$, then washed twice in sterile water, and centrifuged again. The obtained pellet was suspended in $0.1 \mathrm{~mL}$ of lysis buffer $(200 \mathrm{mM}$ Tris-HCl, $\mathrm{pH}$ 7.5; 0.5\% SDS; 30 mM EDTA) and incubated at $70^{\circ} \mathrm{C}$ for $15 \mathrm{~min}$.

Furthermore, $0.1 \mathrm{~mL}$ of a $2.5 \mathrm{M}$ potassium acetate solution was added and incubated at $20^{\circ} \mathrm{C}$ for $20 \mathrm{~min}$. Subsequently, $0.3 \mathrm{~mL}$ of phenol:chloroform:isoamyl alcohol mixture (25:24:1) was added and vortexed for $1 \mathrm{~min}$, and the sample was centrifuged once again (10 min, 13,000 rpm).

The top layer was gently pipetted from the sample and transferred to new Eppendorf tubes. 2-Propanol was added to the mixture and centrifuged (20 min; 13,000 rpm). Subsequently, the supernatant was decanted, and the remaining pellet was rinsed with $70 \%$ 
ethanol and centrifuged again (20 min, 13,000 rpm). After centrifugation, ethanol was decanted, and the isolated DNA was suspended in $0.03 \mathrm{~mL}$ of sterile nuclease-free water. The genetic material was stored at $4{ }^{\circ} \mathrm{C}$ for further analysis.

\subsubsection{Yeast identification using API tests}

The precise identification system API $20 \mathrm{C}$ AUX (bioMérieux, France) was used for the identification of the obtained yeast strains, in accordance with the manufacturer's instructions.

\subsubsection{DNA amplification and agarose gel electrophoresis}

$\begin{array}{ccc}\text { Specific } & \text { primers ITS } 1 \text { (5'- } \\ \text { CGGGATCCGTAGGTGAACCTGCGG-3') } \\ \text { and }\end{array}$
CGGGATCCTCCGCTTATTGATATG-3') (a concentration of 20 pmol each) were used in the PCR process to amplify internally transcribed gene regions (ITS) and 5.8S rDNA. $\mathrm{MgCl}_{2}(1.5 \mathrm{mM} / \mathrm{L}), 0.25 \mathrm{mmol} / \mathrm{L} \mathrm{dNTP}, 0.5 \mathrm{U}$ Taq polymerase (Fermentas, Lithuania) were added to the template DNA at a concentration of $300 \mathrm{ng} / \mu \mathrm{L}(3 \mu \mathrm{L})$.

The amplification reaction was carried out in a Mastercycler gradient thermocycler (Eppendorf, Germany) according to the following program: predenaturation at $94^{\circ} \mathrm{C}$ for $120 \mathrm{~s}$, followed by 34 cycles: at $94^{\circ} \mathrm{C}$ for $30 \mathrm{~s}$, at $53^{\circ} \mathrm{C}$ for $30 \mathrm{~s}$, at $72^{\circ} \mathrm{C}$ for $60 \mathrm{~s}$, and at $72^{\circ} \mathrm{C}$ for $30 \mathrm{~s}$.

The obtained PCR products were separated by using $1.5 \%$ agarose gel added with Midori Green DNA Stain reagent $(2 \mu \mathrm{L})$ in $1 \times$ TAE buffer $(40 \mathrm{mM}$ Tris- $\mathrm{HCl}, 20 \mathrm{mM}$ acetic acid, and $1 \mathrm{mM}$ disodium edetate). The GeneRuler 1 $\mathrm{kb}$ DNA Ladder molecular weight marker (ready-to-use; Thermo Fisher Scientific, USA) was used to determine the size of the resulting bands.

The parameters of the electrophoresis process were $70 \mathrm{~mA}$ and $120 \mathrm{~V}$. During visualization, Quantity One 4.2.1 program (Bio-Rad, Poland) was used to read the molecular masses of the amplified DNA.

\subsubsection{Sequencing of genetic material}

The PCR products were sequenced at Genomed S.A. (Warsaw, Poland) by enzymatic synthesis (Sanger's dideoxy). The yeasts were identified by sequence comparison with the Genbank ${ }^{\circledR}$ genetic sequence database, NCBI (https://blast.ncbi.nlm.nih.gov/Blast.cgi), using the BLAST sequence analysis tool.

\section{Results and discussion}

\subsection{Macro- and microscopic evaluation of yeast isolated from bee bread}

It is highly necessary to conduct a microbiological analysis on bee products in order to ensure consumer safety and for the development of new technologies. Numerous scientific publications (DeGrandi-Hoffman et al., 2013; Kaplan et al., 2016; Kieliszek et al., 2018) confirm the variability of the contaminating microflora depending on the origin of the bee bread (botanical and geographical).

The present study found only one strain of yeast belonging to the genus Rhodotorula. A uniform growth pattern of both yeast strains was noted on the YPG solid medium after 2 days of cultivation at $28^{\circ} \mathrm{C}$. The colonies exhibited pink-salmon color with a dull surface and a compact structure (Fig. 2A). The yeast cells were spherical and ovoid in shape with a vacuole located at the center of the cell. Rhodotorula MK1 yeasts had an average length of $3.50 \pm 0.11 \mu \mathrm{m}$ and a width of $3.07 \pm 0.09$ $\mu \mathrm{m}$ (Fig. 2B).

Owing to the diversity and proven ability to produce potential metabolites, Rhodotorula yeast is used for producing many commercially bioactive compounds and natural pigments, such as carotenoids (Kot et al., 2016). The identified Rhodotorula strains were found to belong to red yeast as they were characterized by a pink-colored colony. A typical feature of this type of microorganism is the production of carotenoids. These metabolites are naturally occurring lipid-soluble pigments (Ram et al., 2020) and can exhibit yellow, orange, and red colors (Yoo et al., 2016). 

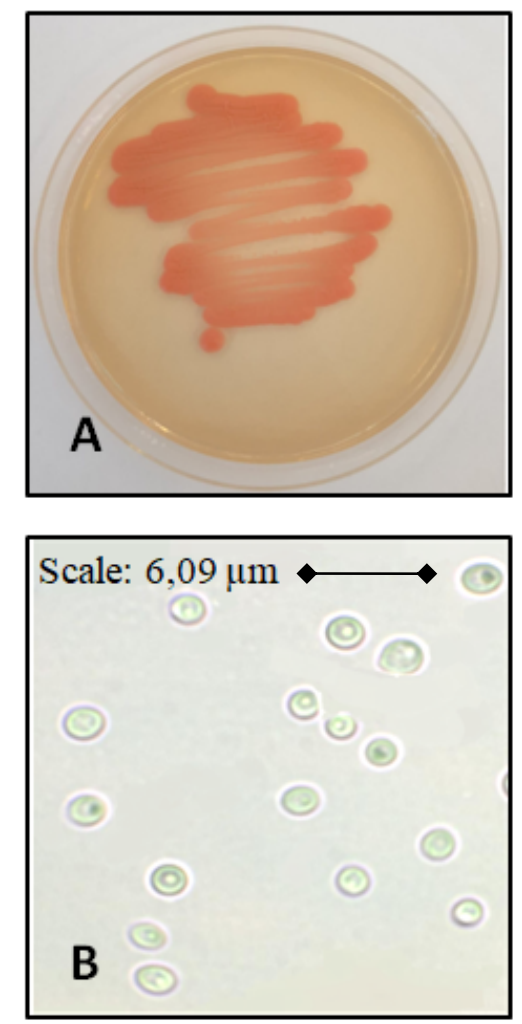

Figure 2. Yeast biomass on YPD agar medium (A); Exemplary microscopic photographs of Rhodotorula (B).

Since the beginning of the 21 st century, the diversity of microorganisms (including yeasts) in bees and their food sources has been increasingly studied. The work of Thai scientists (Saksinchai et al., 2012) confirmed the validity of yeast studies in bee products. The authors managed to isolate as many as 186 yeast strains. Based on the morphological and physiological characteristics, 55 representative strains were identified (including Zygosaccharomyces siamensis).

Bee bread is a source of various species of yeast used in the production of mead. The study conducted by Silva et al. (2020) showed that bee products can contain the microorganisms used for the fermentation of alcoholic beverages. The following yeast species were isolated during the research: Papiliotrema flavescens, Rhodotorula mucilaginosa, Saccharomyces cerevisiae, and Starmerella meliponinorum. Similar dependencies were reported by Čadež et al. (2015). The authors isolated five new strains of Zygosaccharomyces from Hungarian bee bread. It is noteworthy that the obtained microorganisms cannot grow on ordinary yeast nutrients; however, they develop well on media with a high content of sugar. Research by Brysch-Herzberg et al. (2019) showed the presence of Schizosaccharomyces strains of osmophilic yeast in bee bread (originating from Germany).

\subsection{Strain identification (API 20C)}

After conducting the API $20 \mathrm{C}$ AUX test, the obtained results allow the conclusion that the first identified strain was R. mucilaginosa MK1. The tested strain was able to metabolize i.a. glucose, arabinose, sucrose, galactose (Table 1).

It is noteworthy that Rhodotorula yeast is widely used in industries owing to its potential to produce several interesting compounds such as carotenoids and lipids in significant amounts (Kot et al., 2019). From their research, Prabhu et al. (2019) found that the strain of $R$. mucilaginosa belongs to the class of oily microorganisms, because, when grown in a bioreactor, it accumulates lipids up to $25 \%$ of dry substance.

The outstanding biotechnological properties of the strain $R$. mucilaginosa are widely mentioned in the scientific literature. The yeast species $R$. mucilaginosa is considered as a valuable source of carotenoids and has a potential commercial value. However, the low carotenoid production limits its commercial use (Wang et al., 2017).

Further research aimed at determining the biochemical properties of the isolated strain of bee yeast is required. In this study, molecular identification of the isolated yeast species was performed for a more detailed analysis. 
Table 1. Biochemical results for the yeast strain.

\begin{tabular}{|c|c|}
\hline Sugars & $\begin{array}{c}\text { Rhodotorula } \\
\text { MK1 }\end{array}$ \\
\hline Glucose & + \\
\hline Glycerol & - \\
\hline $\begin{array}{l}\text { Calcium 2-keto- } \\
\text { gluconate }\end{array}$ & - \\
\hline Arabinose & + \\
\hline Xylose & + \\
\hline Adonitol & + \\
\hline Xylitol & + \\
\hline Galactose & + \\
\hline Inositol & - \\
\hline Sorbitol & + \\
\hline $\begin{array}{c}\text { Methyl- } \alpha \mathrm{D}- \\
\text { glucopyranoside }\end{array}$ & - \\
\hline $\mathrm{N}$-acetyl-glucosamine & - \\
\hline Cellobiose & - \\
\hline Lactose & - \\
\hline Maltose & + \\
\hline Saccharose & + \\
\hline Trehalose & + \\
\hline Melezitose & + \\
\hline Rafinose & + \\
\hline
\end{tabular}

\subsection{Molecular identification of yeast}

The DNA amplification products with primers ITS1 and ITS4 were analyzed to confirm that a given strain of yeast isolated from bee belongs to the Rhodotorula genus. The PCR products separated by agarose gel electrophoresis are shown in Fig. 3.

A band with a mass of about $640 \mathrm{bp}$ was obtained from the analyses. By comparing the results with the current scientific literature, it can be concluded that the mass of the PCR product bands is characteristic of the species $R$. mucilaginosa. Esteve-Zarzoso et al. (1999) determined the band weight of various yeast strains of Rhodotorula genus: R. acuta, $675 \mathrm{bp}$; $R$. minute, $660 \mathrm{bp}$; and $R$. mucilaginosa $640 \mathrm{bp}$. The obtained yeast strain was deposited in the Culture Collection of the Department of Food Biotechnology and Microbiology of the Warsaw University of Life Sciences (SGGW) as MK1. In addition, the information of the obtained yeast was documented in a file with
GenBank (NCBI) under number LC527461.1. BLAST analysis showed 100\% identity, including the following sequences: MT465994.1, MK805510.1, and MT328138.1.

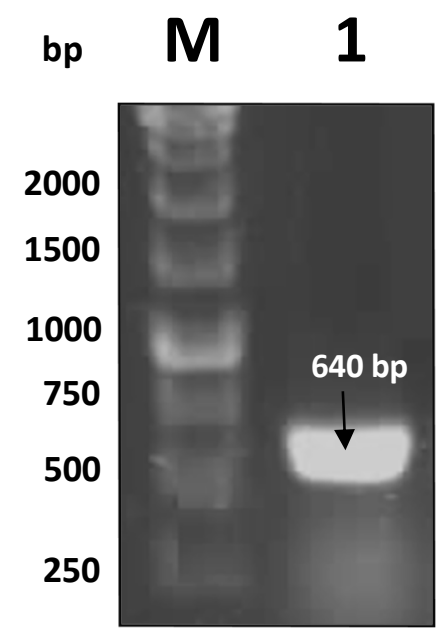

Figure 3. PCR gel electrophoresis of yeast from the bee bread (M-marker, 1Rhodotorula MK1).

Of note, various scientific publications state that $R$. mucilaginosa yeast was isolated not only from fermented milk but also from various extreme ecosystems, for example, sea and glacial shores, products of plant origin, and industrial areas polluted with hydrocarbons (Deligios et al., 2015). Observations by Tartor et al. (2018) confirmed our results showing that the DNA amplification product of the yeast $R$. mucilaginosa isolated from diseased freshwater fish was approximately $640 \mathrm{bp}$.

In conclusion, the yeasts isolated from different natural environments exhibit outstanding biochemical features that can be applied in various branches of the biotechnology industry.

\section{Conclusions}

The results confirm the need for research on the microflora contaminating bees. In our attempts to determine the presence of yeast in bee bread, we isolated the strain Rhodotorula MK1. In the future, particular attention will be paid to the determination of new strains of 
microorganisms in other bee products (e.g., propolis) and their biochemical characteristics.

\section{References}

Babarinde, G.O., Babarinde, S.A., Lomuwagun, T.O., Ojo C.O. (2018). Quality assessment of nigerian multiflora honey marketed in ogbomoso region. Carpathian Journal of Food Science \& Technology, 10(3), 108-117.

Brysch-Herzberg, M., Tobias, A., Seidel, M., Wittmann, R., Wohlmann, E., Fischer, R., Dlauchy, D., Gabor, P. (2019). Schizosaccharomyces osmophilus sp. nov., an osmophilic fission yeast occurring in bee bread of different solitary bee species. FEMS Yeast Research, 19(4), foz038. doi:10.1093/femsyr/foz038

Bzducha-Wróbel, A., Kieliszek, M., Błażejak, S. (2013). Chemical composition of the cell wall of probiotic and brewer's yeast in response to cultivation medium with glycerol as a carbon source. European Food Research and Technology, 237(4), 489-499. doi:10.1007/s00217-013-2016-8

Čadež, N., Fülöp, L., Dlauchy, D., Gábor P. (2015). Zygosaccharomyces favi sp. nov., an obligate osmophilic yeast species from bee bread and honey. Antonie van Leeuwenhoek, 107, 645-654. doi:10.1007/s10482-014-0359-1

de Arruda, V.A.S., Vieria dos Santos, A., Figueiredo Sampaio, D., da Silva Araújo, E., de Castro Peixoto, A. L., Estevinho, M.L.F., Bicudo de Almeida-Muradian, L. (2017). Microbiological quality and physicochemical characterization of Brazilian bee pollen. Journal of Apicultural Research, 56(3), 231-238.

Doi:10.1080/00218839.2017.1307715

DeGrandi-Hoffman, G., Eckholm, B. J., Huang, M. H. (2013). A comparison of bee bread made by Africanized and European honey bees (Apis mellifera) and its effects on hemolymph protein titers. Apidologie, 44(1), 52-63. Doi:10.1007/s13592-0120154-9
Deligios, M., Fraumene, C., Abbondio, M., Mannazzu, I., Tanca, A., Addis, M. F., \& Uzzau, S. (2015). Draft genome sequence of Rhodotorula mucilaginosa, an emergent opportunistic pathogen. Genome Announcements, 3(2), e00201-15, doi:10.1128/genomeA.00201-15

Esteve-Zarzoso, B., Belloch, C., Uruburu, F., Querol, A. (1999). Identification of yeasts by RFLP analysis of the $5.8 \mathrm{~S}$ rRNA gene and the two ribosomal internal transcribed spacers. International Journal of Systematic and Evolutionary Microbiology, 49(1), 329337. doi:10.1099/00207713-49-1-329

Gilliam, M., Prest, D.B., Lorenz, B.J. (1989). Microbiology of pollen and bee bread: taxonomy and enzymology of molds. Apidologie, 20(1), 53-68. doi:10.1051/apido:19890106

Gilliam, M. (1997). Identification and roles of non-pathogenic microflora associated with honey bees. FEMS Microbiology Letters, 155(1), 1-10. doi: 10.1016/S03781097(97)00337-6

Janashia, I., Choiset, Y., Jozefiak, D., Choiset, Y., Jozefiak, D., Déniel, F., Coton, E., Moosavi-Movahedi, A.A., Chanishvili, N., Haertlé, T. (2018). Beneficial protective role of endogenous lactic acid bacteria against mycotic contamination of honeybee beebread. Probiotics and Antimicrobial Proteins, 10, 638-646. doi:10.1007/s12602017-9379-2

Kaplan, M., Karaoglu, Ö., Eroglu, N., Silici, S. (2016). Fatty acid and proximate composition of bee bread. Food Technology and Biotechnology, 54(4), 497-504. doi:10.17113/ftb.54.04.16.4635

Khalifa, S.A., Elashal, M., Kieliszek, M., Ghazala, N.E., Farag, M.A., Saeedh, A., Xiao, J., Zou, X., Khatib, A., Göransson, U., El-Seedi, H.R. (2020). Recent insights into chemical and pharmacological studies of bee bread. Trends in Food Science and Technology, 97, 300-316. doi:10.1016/j.tifs.2019.08.021

Kieliszek, M., Piwowarek, K., Kot, A.M., Błażejak, S., Chlebowska-Śmigiel, A., 
Wolska, I. (2018). Pollen and bee bread as new health-oriented products: A review. Trends in Food Science and Technology, 71, 170-180. doi:10.1016/j.tifs.2017.10.021

Kot, A. M., Błażejak, S., Kieliszek, M., Gientka, I., \& Bryś, J. (2019). Simultaneous production of lipids and carotenoids by the red yeast Rhodotorula from waste glycerol fraction and potato wastewater. Applied Biochemistry and Biotechnology, 189(2), 589-607. doi:10.1007/s12010-019-03023-z

Kot, A.M., Błażejak, S., Kurcz, A., Gientka, I., Kieliszek, M. (2016). Rhodotorula glutinis - potential source of lipids, carotenoids, and enzymes for use in industries. Applied Microbiology and Biotechnology, 100(14), 6103-6117. doi:10.1007/s00253-016-7611-8

Nogueira, C., Iglesias, A., Feás, X., Estevinho, L. M. (2012). Commercial bee pollen with different geographical origins: a comprehensive approach. International Journal of Molecular Sciences, 13(9), 11173-11187. doi: 10.3390/ijms130911173

Prabhu, A.A., Gadela, R., Bharali, B., Deshavath, N.N., Dasu, V.V. (2019). Development of high biomass and lipid yielding medium for newly isolated Rhodotorula mucilaginosa. Fuel, 239, 874885. doi:10.1016/j.fuel.2018.11.088

Ram, S., Mitra, M., Shah, F., Tirkey, S. R., Mishra, S. (2020). Bacteria as an alternate biofactory for carotenoid production: A review of its applications, opportunities and challenges. Journal of Functional Foods, 67, 103867. doi:10.1016/j.jff.2020.103867

Saksinchai, S., Suzuki, M., Chantawannakul, P., Ohkuma, M., Lumyong, S. (2012). A novel ascosporogenous yeast species, Zygosaccharomyces siamensis, and the sugar tolerant yeasts associated with raw honey collected in Thailand. Fungal Diversity, 52(1), 123-139. doi:10.1007/s 13225-011-0115-z

Silva, M.S., Arruda, L.M., Xavier, P.L., Ramirez, M.X., Silverira F., Santana, C.W., Gomes, L., Eller, M.R. (2020). Selection of yeasts from bee products for alcoholic beverage production. Brazilian Journal of Microbiology, 51 , doi:10.1007/s42770-019-00184-1.

Tartor, Y., Taha, M., Mahboub, H., El Ghamery, M. (2018). Yeast species associated with diseased fish: Occurrence, identification, experimental challenges and antifungal susceptibility testing. Aquaculture, 488, 134-144. doi:10.1016/j.aquaculture.2018.01.033

Tomás, A., Falcão, S. I., Russo-Almeida, P., Vilas-Boas, M. (2017). Potentialities of beebread as a food supplement and source of nutraceuticals: Botanical origin, nutritional composition and antioxidant activity. Journal of Apicultural Research, 56(3),219-230. doi:10.1080/00218839.2017.1294526

Wang, Q., Liu, D., Yang, Q., Wang, P. (2017). Enhancing carotenoid production in Rhodotorula mucilaginosa $\mathrm{KC} 8$ by combining mutation and metabolic engineering. Annals of Microbiology, 67, 425-431. doi:10.1007/s13213-017-1274-2

Yoo, A.Y., Kweon, J., Alnaeeli, M. (2016). Production control and characterization of antibacterial carotenoids from the yeast Rhodotorula mucilaginosa AY-01. Process Biochemistry, 51, 463-473. doi:10.1016/j.procbio.2016.01.008 